\title{
Electronic Excitation and Thermodynamic Properties of High Temperature Gases
}

\author{
M. Capitelli, E. Ficocelli V. and E. Molinari \\ Centro di Studio per la Chimica dei Plasmi del C.N.R., \\ Istituto di Chimica Generale e Inorganica dell’Università, Bari (Italy) \\ (Z. Naturforsch. 26 a, 672-683 [1971] ; received 10 November 1970)
}

\begin{abstract}
Different cut-off criteria of partition functions have been utilized in order to evaluate the contribution of electronic excitation to thermodynamic properties of high temperature gases $\left(5000{ }^{\circ} \mathrm{K}\right.$ to $\left.35000^{\circ} \mathrm{K}, 10^{-2}-10 \mathrm{~atm}\right)$.

It is shown that properties of single species are strongly affected by the cut-off criterion adopted, i. e. the contribution of electronic excitation to these properties is important.

It is also shown that the reported absence of this contribution to total enthalpies and specific heats of plasmas is the result of an almost complete compensation between "reactional" and "frozen" terms which are all dependent on electronic excitation.
\end{abstract}

\section{Introduction}

Accurate values of electronic partition functions of gases up to $35,000{ }^{\circ} \mathrm{K}$ are presently available ${ }^{1-4}$ and have been obtained by completion of the observed energy levels of the relevant species and by applying the cut-off criteria proposed by MARGENAU and LEWIS ${ }^{5}$ and by GRIEM ${ }^{6}$. Equilibrium properties derived from these partition functions are at present the most accurate ones available. These data can therefore be taken as a guiding reference for less accurate calculations in which the ground state only, or a few levels above it, are included in the partition functions.

A comparison among these methods of calculation shows that "total" specific heats and thermodynamic functions do not differ by more than a few percent up to $35,000{ }^{\circ} \mathrm{K}$. Equilibrium compositions appear to be affected by the introduction of electronic levels only as far as minority species are concerned.

Reprints request to Prof. E. Molinari, Istituto di Chimica Generale e Inorganica dell'Università, Via Amendola, 173, I-70126 Bari (Italy).

1 K. S. Drellishak, C. F. Knopp, and A. B. Cambel, Partition Functions and Thermodynamic Properties of Argon Plasmas, AEDC-TDR No. 63-146 [1963].

2 K. S. Drellishak, D. P. Aeschliman, and A. B. Cambel, Tables of Thermodynamic Properties of Argon, Nitrogen and Oxygen Plasmas, AEDC-TDR No. 64-12 [1964].

3 M. Capitelli, E. Ficocelli V., and E. Molinari, Equilibrium Compositions and Thermodynamic Properties of Mixed Plasmas: I $\mathrm{He}-\mathrm{N}_{2}, \mathrm{Ar}-\mathrm{N}_{2}$ and $\mathrm{Xe}-\mathrm{N}_{2}$ plasmas at one atmosphere, between $5000{ }^{\circ} \mathrm{K}$ and $35000^{\circ} \mathrm{K}$, Bari [1969] (Report available upon request).

${ }^{4}$ M. Capitelli, E. Ficocelli V., and E. Molinari, Equilibrium Compositions and Thermodynamic Properties of
The conclusion that the contribution of electronic excitation can be neglected in the calculation of these properties appears therefore rather obvious.

This conclusion has been extended to "frozen" properties of plasmas ${ }^{7}$, which have also been calculated without the inclusion of the electronic contribution, and to properties of single species ${ }^{8}$.

However, more recent calculations ${ }^{9}$ in which the cut-off criterion of Griem has been applied to completed sets of energy levels, have shown that specific heats of single species can be strongly affected by the introduction of energy levels and by the cut-off criterion adopted. This is also true for the "frozen" enthalpy and the "frozen" specific heats of plas$\operatorname{mas}^{10}$.

It has furthermore been shown, in the case of "total" specific heats, that the observed independence from electronic excitation arises from an almost complete compensation between the "frozen" and the "reactional" contribution to $C_{p \text {,tot }}{ }^{11}$.

Mixed Plasmas: II Ar- $\mathrm{O}_{2}$ plasmas at $10^{-2}-10 \mathrm{~atm}$, between $2000^{\circ} \mathrm{K}$ and $35000^{\circ} \mathrm{K}$, Bari [1970] (Report available upon request).

5 H. Margenau and M. Lewis, Rev. Mod. Phys. 31, 594 [1959].

6 H. R. Griem, Phys. Rev. 128, 1280 [1962].

7 C. H. BACK, Phys. Fluids 10, 807 [1967].

8 B. Albhorn and M. Salvat, Z. Naturforsch. 22 a, 260 [1967].

9 M. Capitelli and E. Molinari, J. Plasma Phys. 4, 335 [1970].

10 M. Capitelli and E. Ficocelli V., Z. Naturforsch. 25 a, 977 [1970].

11 M. Capitelli and E. Ficocelli V., J. Plasma Phys. 5, 115 [1971]. 
This result suggests that electronic excitation might be contributing to "total" quantities as well but that this contribution is actually masked by compensation effects occurring among the various terms into which these quantities can be separated. It is therefore the purpose of the present work to examine in some detail the problem of the contribution of electronic excitation to the various equilibrium properties of plasmas, and this will be done by a systematic application of three different cut-off criteria.

\section{The Cut-off of Partition Functions}

In the evaluation of the electronic partition functions $Q_{\mathrm{e} j}$ of a species $j$

$$
\begin{aligned}
& Q_{\mathrm{e} j}=\sum_{n}^{n^{\max }} g_{n j} \exp \left\{-E_{n j} / k T\right\} \text { or } \\
& Q_{\mathrm{e} j}=\sum_{0}^{E_{n j \max }} g_{n j} \exp \left\{-E_{n j} / k T\right\}
\end{aligned}
$$

it is necessary to resort to some cut-off criterion of the partition function in order to avoid the divergence of the summation ${ }^{12}$. The following criteria have most extensively been used in recent times.

\section{a) The criterion of MARgenAu and Lewis ${ }^{1,2,5}$}

The partition function is cut at a value of the quantum number $n$ given by :

$$
n_{\max }=36.11 \cdot 10^{3}\left(\frac{Z_{j e f r}^{2} \cdot T}{\sum n_{j} z_{j}^{2}}\right)^{1 / 4},
$$

where $Z_{j \text { eff }}$ is the effective charge of the $j$-th species and $n_{j}$ the number density $\left(\mathrm{cm}^{-3}\right)$ of the species with charge $z_{j}$.

This criterion represents the upper limit of the cut-off criteria adopted.

\section{b) The criterion of GRIEM ${ }^{3,6,9}$}

The partition function is cut at a maximum value of $E_{n}$ given by:

$$
E_{n j_{\max }}=E_{0 \mathrm{j}}-\Delta E_{0 j}
$$

with $\Delta E_{0 j}=2\left(z_{j}+1\right) e^{3}(\pi / k T)^{1 / 2}\left(\sum n_{j} z_{j}^{2}\right)^{1 / 2}$

where $E_{0 j}$ and $\Delta E_{0 j}$ are the ionization potential and the lowering of the ionization potential in the plasma.

12 H. W. Drawin and P. Felenbok, Data for Plasmas in Local Thermodynamic Equilibrium, Gauthier-Villars, Paris 1965. c) The ground state method

$$
Q_{\mathrm{e} j}=g_{0 j} .
$$

Once the cut-off criterion has been selected the procedure for the calculation of equilibrium properties is straightforward ${ }^{3,9}$.

\section{Properties of Single Species}

\section{a) Partition functions and their derivatives with respect to temperature}

Values of $Q_{\mathrm{e} j}$ calculated at different pressures for nitrogen species according to the three methods mentioned in the preceding section have been plotted as a function of temperature in Figure 1.

Corresponding values of

$$
\dot{Q}_{\mathrm{e} j}=\frac{\mathrm{d} \ln Q_{\mathrm{e} j}}{\mathrm{~d} \ln T} \text { and of } \quad \ddot{Q}_{\mathrm{e} j}=\frac{\mathrm{d}^{2} \ln Q_{\mathrm{e} j}}{\mathrm{~d}^{2} \ln T}
$$

can be found in Figures 2 and 3 respectively.

A comparison of these quantities calculated at one atmosphere according to the Griem's criterion and to a criterion in which the first levels above the fundamental are included in $Q_{\mathrm{e} j}$ can be found in Ref. ${ }^{9}$ for other species as well as for nitrogen species diluted in helium, argon and xenon. Values for oxygen at $0.01-10 \mathrm{~atm}$ can be found in Ref. ${ }^{4}$. It should be remarked that the large difference observed in the values of $Q_{\mathrm{e} j}$ and of its derivatives, when different cut-off criteria are applied, are to a large extent attributable to the use of completed sets of energy levels, as already discussed in references ${ }^{9,13}$.

When use is made of the observed energy levels only, the partition function is raised above its ground state value to an extent depending on the species considered but $Q_{\mathrm{e} j}$ remains practically insensitive to the cut-off criterion (Margenau and Lewis or Griem) in that none or a few energy levels only are in this case to be found within the range of levels or of energies involved in the cut-off. On the contrary when completed sets are used the $Q_{\mathrm{e} j}$ become dependent not only on the criterion adopted but also on the more or less hydrogenlike character of the additional levels introduced in the summation ${ }^{9,13}$.

13 M. Capitelli, E. Ficocelli V., and E. Molinari, Rev. Int. Hautes Temp. Refract. 7, 153 [1970]. 


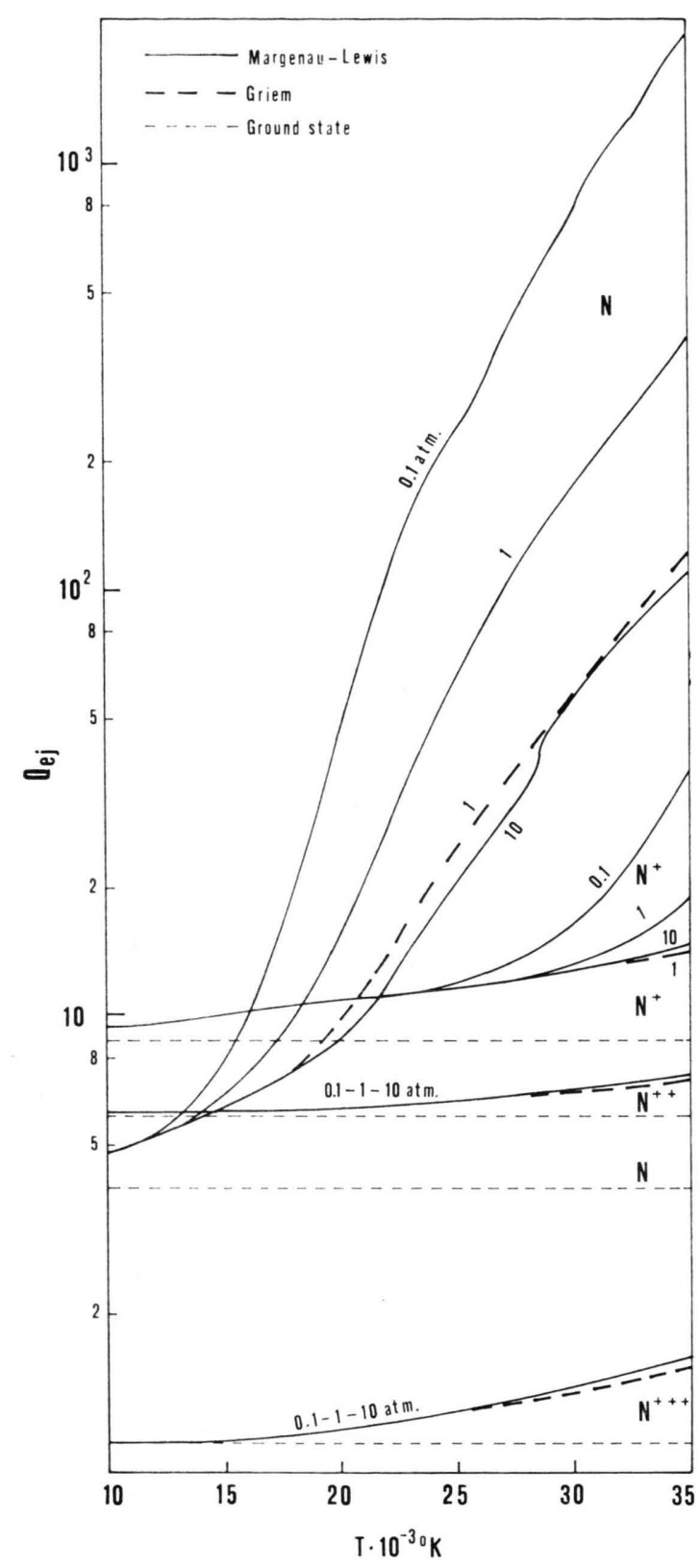

Fig. 1. Partition functions $Q_{\mathrm{e}} j$ at different pressures for the species $\mathrm{N}, \mathrm{N}^{+}, \mathrm{N}^{++}$and $\mathrm{N}^{++}$according to different cut-off criteria.

\section{b) Enthalpies and specific heats}

The enthalpy of a species is obtained from the corresponding partition function by derivation with respect to temperature

$$
H_{j}-\varepsilon_{j}=R T\left(\frac{\partial \ln q_{j}}{\partial \ln T}\right)_{p}(\mathrm{cal} / \mathrm{mole})
$$

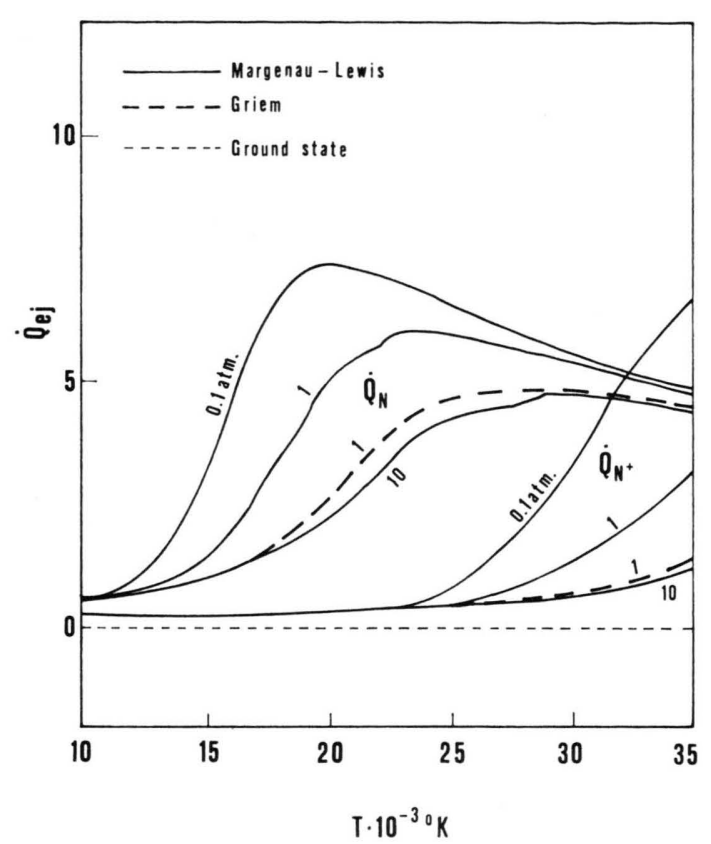

Fig. 2. Values of $\dot{Q}_{\mathrm{e} j}$ at different pressures for the species $\mathrm{N}$ and $\mathrm{N}^{+}$according to different cut-off criteria.

where $q_{j}=Q_{\mathrm{e} j} \cdot Q_{\mathrm{tr}}$ is the total partition function for a monatomic species. $Q_{\mathrm{tr}}$ is the translational partition function

$$
Q_{\operatorname{tr}}=\left(\frac{2 \pi m_{j} k T}{h^{2}}\right)^{3 / 2} \cdot V
$$

and $\varepsilon_{j}$ is the reference level.

Eq. (5) then becomes

$$
H_{j}-\varepsilon_{j}=5 / 2 R T+R T \dot{Q}_{\mathrm{e} j} .
$$

By deriving Eq. (6) with respect to temperature one obtains the specific heat of a single species

$$
C_{\mathrm{p} j}=5 / 2 R+R\left(\dot{Q}_{\mathrm{e} j}+\ddot{Q}_{\mathrm{e} j}\right) \mathrm{cal} / \mathrm{mole}{ }^{\circ} \mathrm{K} .
$$

The behaviour of the derivatives of the electronic partition functions illustrated in Figs. 2 and 3 is immediately reflected by the enthalpies and by the specific heats of the single species, as can be appreciated from Figs. 4 and 5.

As already discussed in Ref. ${ }^{9,13}$ specific heats of a single species can markedly be affected by dilution in different gases. This effect has been found to be particularly important for the species $\mathrm{N}$ diluted in $\mathrm{He}, \mathrm{Ar}$ or $\mathrm{Xe}$ and for the species He diluted in nitrogen. Smaller effects have been observed when $\mathrm{Xe}$ and $\mathrm{Ar}$ are diluted in nitrogen. Here again it should be pointed out that the effect of dilution can only be appreciated when use is made of completed sets of energy levels. 


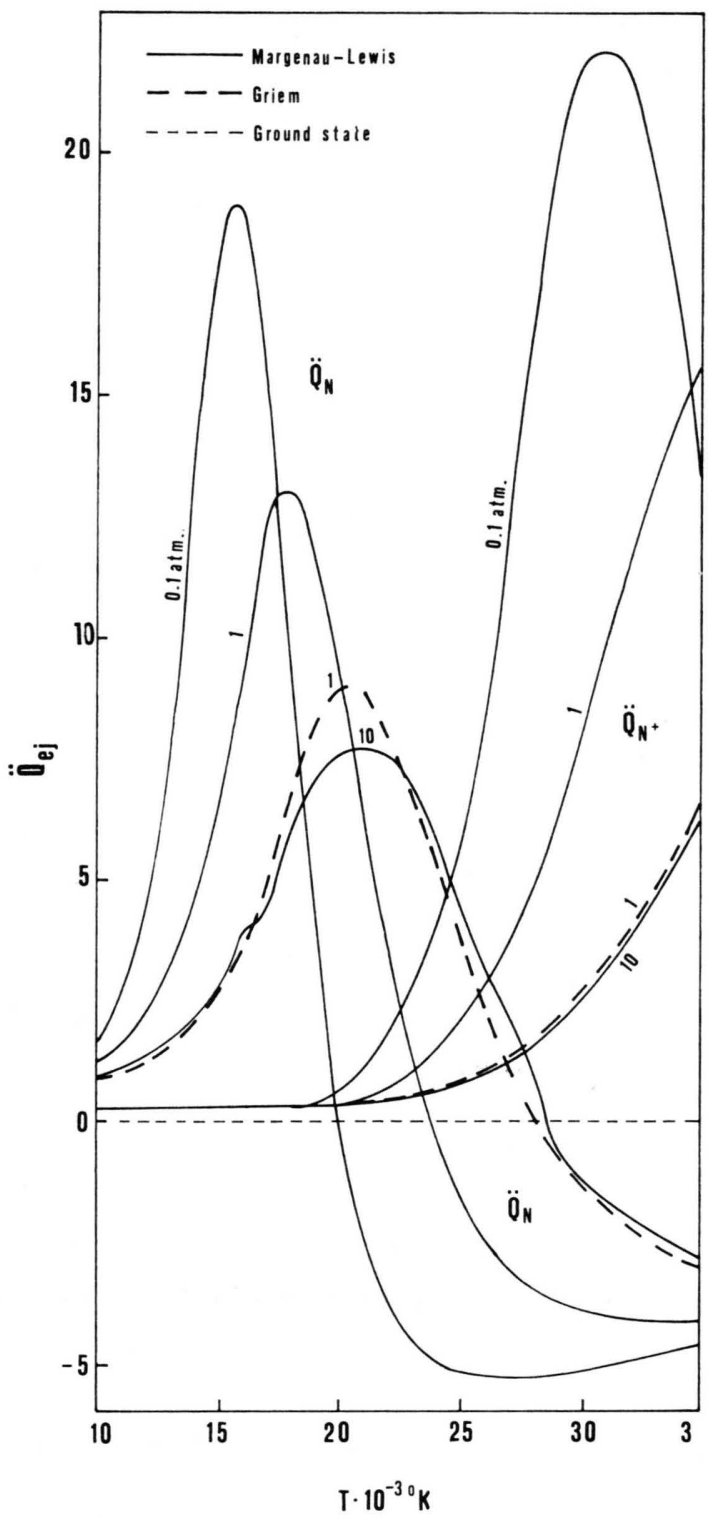

Fig. 3. Values of $\ddot{Q}_{\mathrm{e} j}$ at different pressures for the species N and $\mathrm{N}^{+}$according to different cut-off criteria.

\section{c) Enthalpies of ionization}

The enthalpy change (cal/particle) corresponding to the ionization process $B^{z}=B^{z+1}+\mathrm{e}$ is given by the expression

$\Delta H=5 / 2 k T+k T\left(\dot{Q}_{\mathrm{e} B^{z+1}}-\dot{Q}_{\mathrm{e} B^{z}}\right)+E_{0 B^{z}}-\Delta E_{0 B^{z}}$

where $E_{0 B^{z}}$ is the ionization potential of the species $B^{z}$ and $\Delta E_{0 B^{z}}$ is the corresponding lowering in the plasma. Values of $\Delta H$ for the reactions $\mathrm{N}=\mathrm{N}^{+}+\mathrm{e}$ and $\mathrm{N}^{+}=\mathrm{N}^{++}+\mathrm{e}$ calculated at different pressures

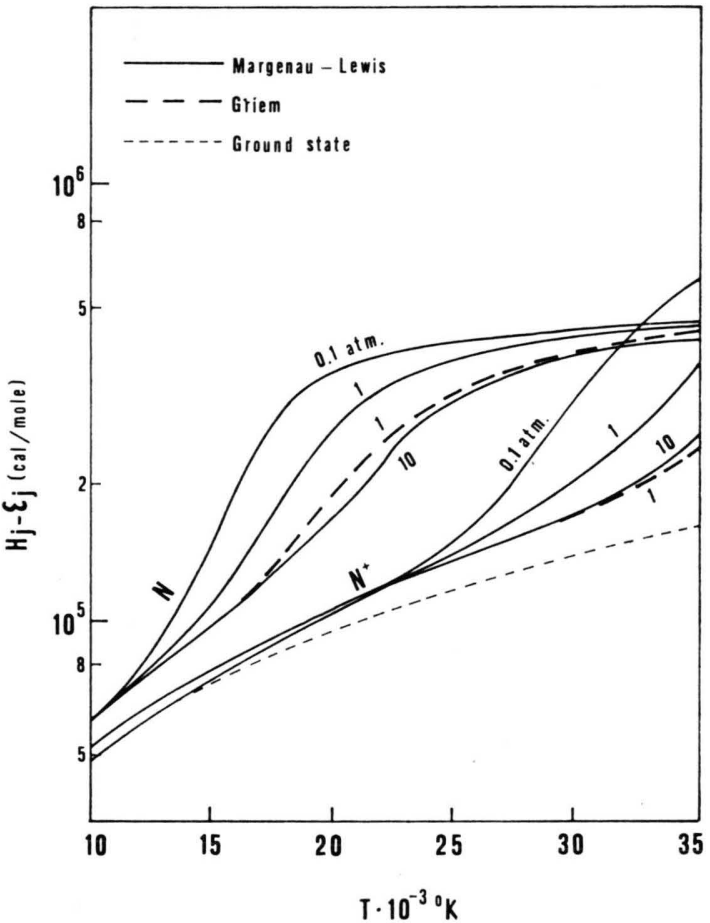

Fig. 4. Enthalpies at different pressures of the species $\mathrm{N}$ and $\mathrm{N}^{+}$according to different cut-off criteria.

according to the three methods have been plotted as a function of temperature in Fig. 6 . The behaviour of the reaction $\mathrm{N}=\mathrm{N}^{+}+\mathrm{e}$ is interesting in that it shows that $\Delta H$ goes through a minimum and can become larger than the ground state value. This is the consequence of taking into account the excitation of both $\mathrm{N}$ and $\mathrm{N}^{+}$which occurs in different temperature ranges. Beyond the minima of the $\Delta \mathrm{H} / \mathrm{T}$ curves the electronic excitation of the ionized species begins to contribute to the $\dot{Q}_{\mathrm{e} B^{z+1}}$ term while the term $\dot{Q}_{\mathrm{e} B^{z}}$ is now decreasing with increasing temperature (compare Fig. 2). The minimum is not present in the reaction $\mathrm{N}^{+}=\mathrm{N}^{++}+\mathrm{e}$ since the $\mathrm{N}^{++}$ species has energy levels which are too high to be appreciably populated in the temperature range examined. Figure 7 reports the results obtained for the reaction $\mathrm{Ar}=\mathrm{Ar}^{+}+\mathrm{e}$. In this figure values of $\Delta H$ calculated by Devoto ${ }^{14}$ according to the Griem's method have been compared with the values obtained by us using the same method. The levels utilized by Devoto for the completion of the observed set of energy levels are more hydrogenlike than

14 R. S. Devoto, Tables of the Composition and Transport Coefficients of Partially Ionized Argon, NASA CR-85559. 


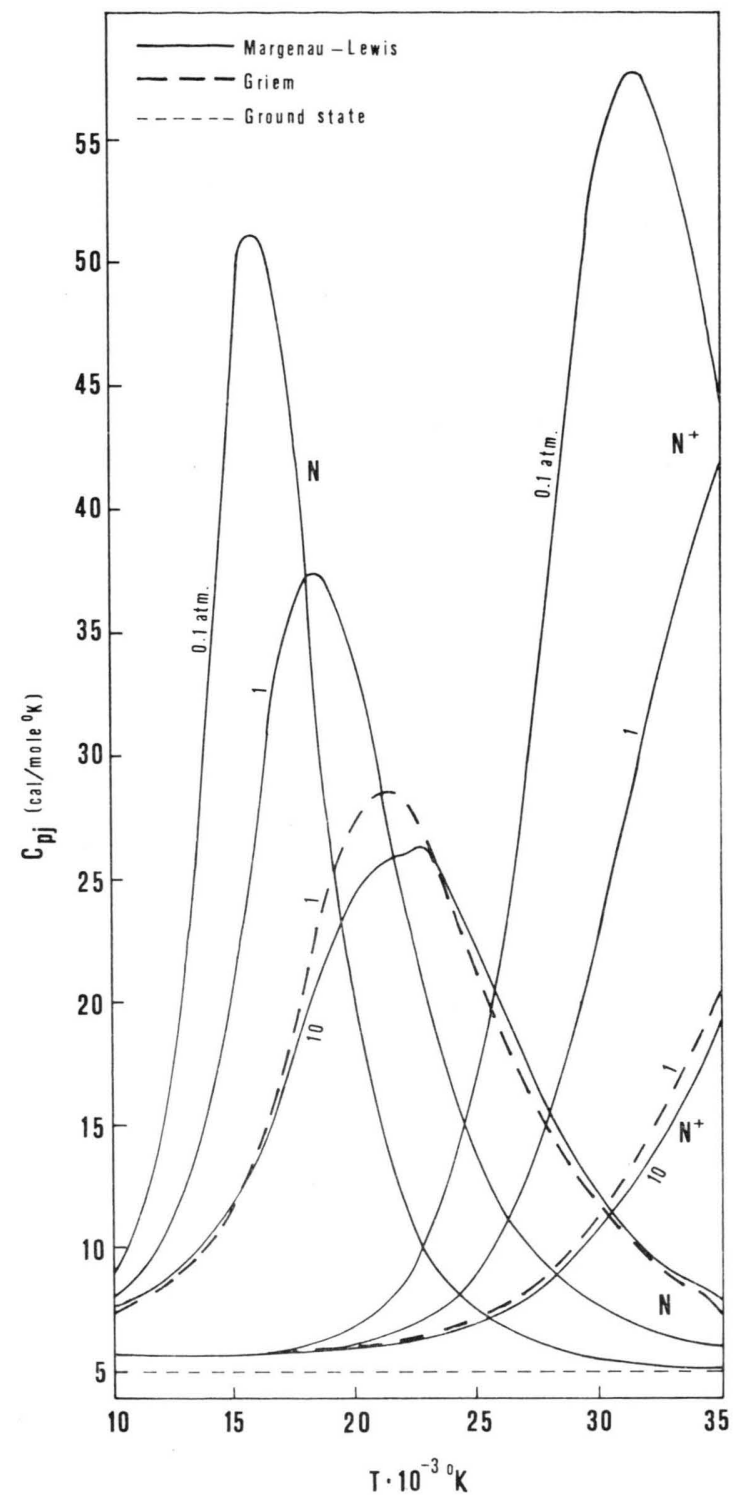

Fig. 5. Specific heats at different pressures of the species $\mathrm{N}$ and $\mathrm{N}^{+}$according to different cut-off criteria.

those utilized in the present calculations and the differences reported in Fig. 7 can here be ascribed to the different method of evaluation of the missing levels, a fact already pointed out in a preceeding section. In the present calculations a value of $\Delta E_{0}=0$ has been used when applying the ground state method. An alternative choice of $\Delta E_{0}$ has been made by BurHon and WieneCKE ${ }^{15}$ who have also

15 F. Burhon and R. Wienecke, Z. Phys. Chem. 213, 37 [1960].

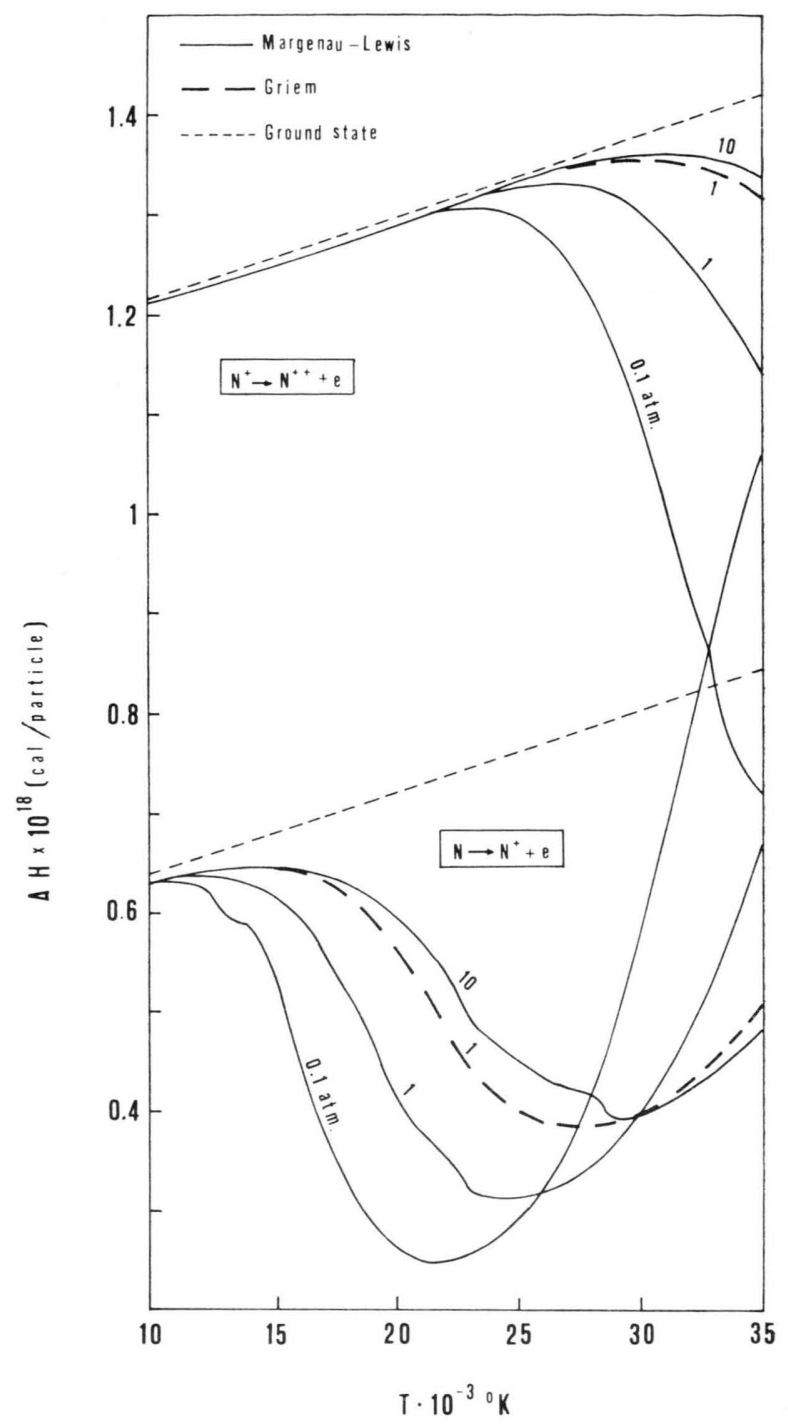

Fig. 6. Enthalpies of ionization at different pressures for the species $\mathrm{N}$ (below) and $\mathrm{N}^{+}$(above) according to different cutoff criteria.

used a ground state method but with

$$
\Delta E_{0}=7 \cdot 10^{-7} \sqrt[3]{n_{\mathrm{e}}} \text { (e. v.), }
$$

according to UNSÖLD ${ }^{16}\left[n_{\mathrm{e}}\right.$ is the electron number density $\left.\left(\mathrm{cm}^{-3}\right)\right]$. Values of $\Delta E_{0}$ calculated according to Unsöld are, as well known, much larger than those evaluated according to either the MARGENAU and LEwIS ${ }^{10}$ or the Griem's method. Values of $\Delta H$ calculated for the reaction $0=0^{+}+\mathrm{e}$ according to

16 A. Unsöld, Phys. Sternatmosphären, Springer-Verlag, Berlin 1956. 


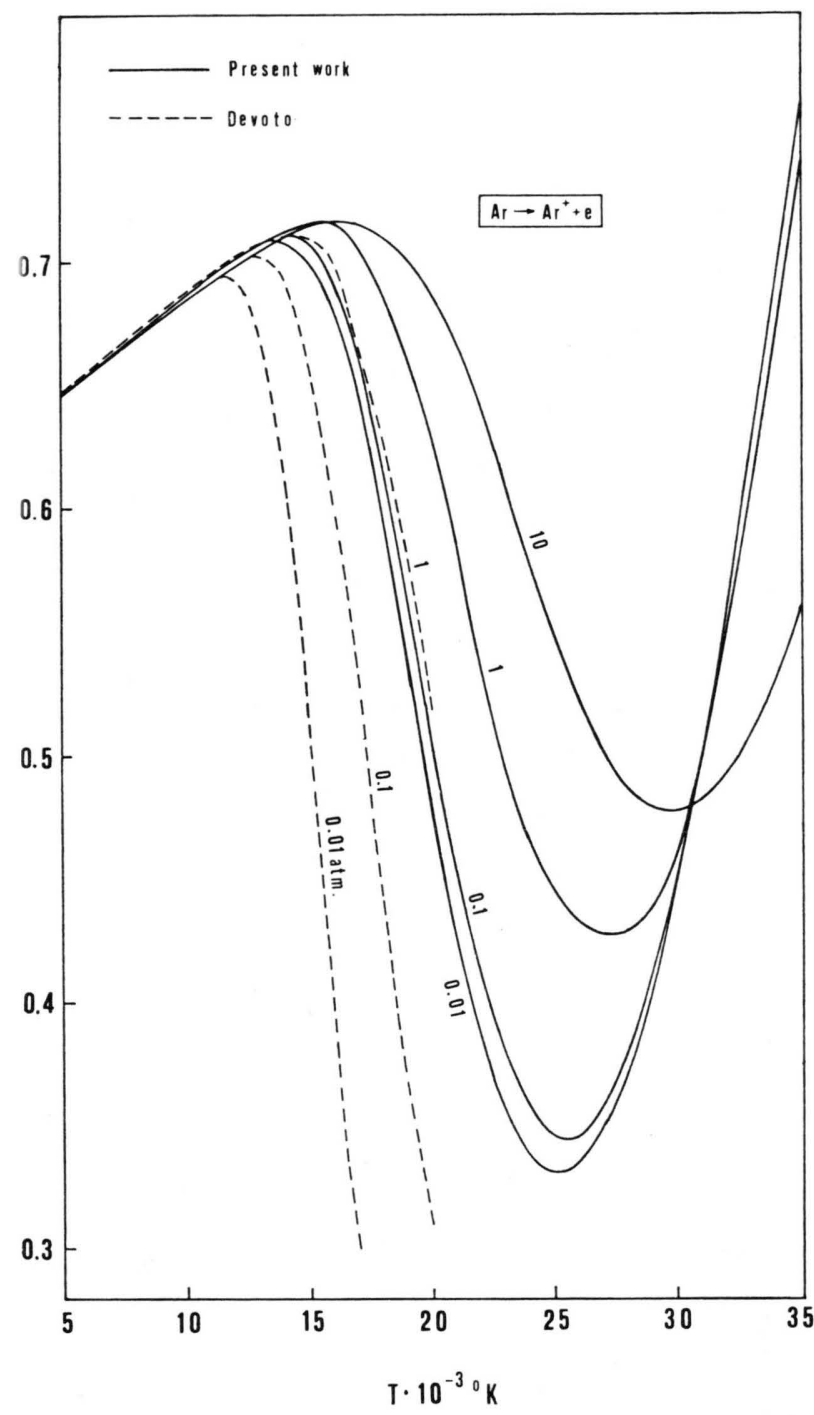

Fig. 7. Enthalpies of ionization at different pressures, for the species Ar according to Devoto and to the present work.

Burhon and Wienecke have been compared in Fig. 8 with the corresponding values determined according to the criterion of Griem and to the ground state method.

\section{Properties of the Plasma}

Values of the Helmholtz potential of the entropy and of the internal energy calculated for helium and nitrogen according to three different cut-off criteria

17 P. Fauchais and N. Manson, XX. Meeting IUPAC, Moscow 1965.

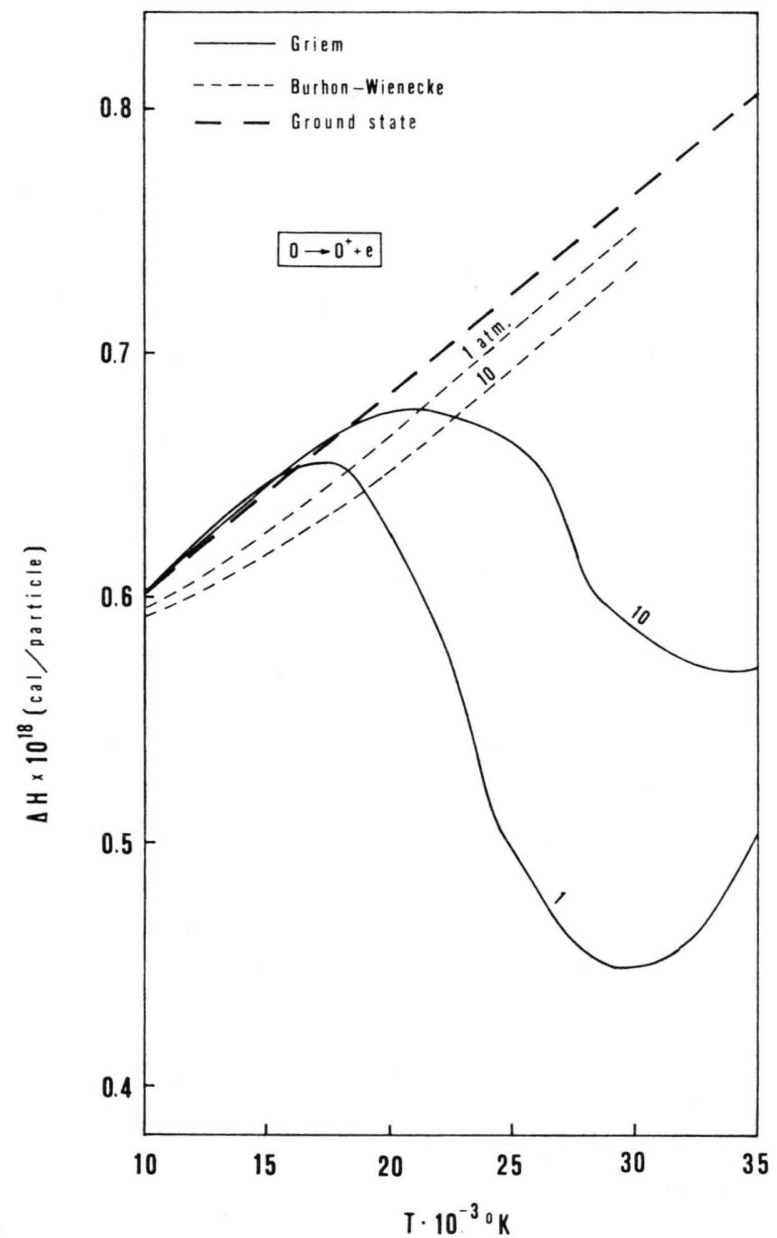

Fig. 8. Enthalpies of ionization at $1-10$ atm for the species 0 according to different cut-off criteria.

have been collected in Table 1 and in Table 2 respectively.

One appreciates from these tables that the contribution of electronic excitation to these functions is at most of the order of a few percent, in marked contrast with the large contribution present when single species are considered. The calculations of thermodynamic functions reported in references ${ }^{17-19}$ confirm this observation.

This contrast can be understood for thermodynamic functions, such as $F$ and $G$ which are dependent on $\ln Q_{\mathrm{e} j}$. It is in fact observed that, in general,

18 F. Fauchais, Rev. Int. Hautes Temp. Refract. 6, 77 [1969].

19 J. C. Hester and K. G. Sewell, J. Appl. Phys. 35, 729 [1964]. 
Table 1. A comparison of thermodynamic properties at various temperatures calculated according to Margenau and Lewis's criterion (columns a), to Griem's criterion (column b) and to the ground state method (columns c) for a Helium plasma.

\begin{tabular}{|c|c|c|c|c|c|c|c|}
\hline \multirow{2}{*}{$\frac{T{ }^{\circ} \mathrm{K}}{10000}$} & $a$ & $c$ & ${ }^{a} \mathrm{He}$ & $\begin{array}{c}1 \text { atm. } \\
b \\
\text { tz Potentio }\end{array}$ & $\mathrm{l} / \mathrm{g}) \quad$ c & \multicolumn{2}{|c|}{10 atm. } \\
\hline & $1.223(5)$ & $1.223(5)$ & $1.109(5)$ & $1.109(5)$ & $1.109(5)$ & $0.995(5)$ & $0.995(5)$ \\
\hline 15000 & $1.920(5)$ & $1.919(5)$ & $1.742(5)$ & $1.742(5)$ & $1.742(5)$ & $1.569(5)$ & $1.569(5)$ \\
\hline 20000 & $2.800(5)$ & $2.798(5)$ & $2.545(5)$ & $2.454(5)$ & $2.453(5)$ & $2.183(5)$ & $2.182(5)$ \\
\hline 25000 & $3.962(5)$ & $3.961(5)$ & $3.403(5)$ & $3.402(5)$ & $3.398(5)$ & $2.912(5)$ & $2.905(5)$ \\
\hline \multirow[t]{2}{*}{35000} & $6.403(5)$ & $6.402(5)$ & $5.608(5)$ & $5.608(5)$ & $5.605(5)$ & $4.818(5)$ & $4.809(5)$ \\
\hline & \multicolumn{7}{|c|}{ Entropy $\left(\mathrm{cal} / \mathrm{g}^{\circ} \mathrm{K}\right)$} \\
\hline 10000 & $1.298(1)$ & $1.298(1)$ & $1.184(1)$ & $1.184(1)$ & $1.184(1)$ & $1.070(1)$ & $1.070(1)$ \\
\hline 15000 & $1.400(1)$ & $1.399(1)$ & $1.250(1)$ & $1.250(1)$ & $1.250(1)$ & $1.125(1)$ & $1.125(1)$ \\
\hline 20000 & $1.924(1)$ & $1.916(1)$ & $1.475(1)$ & $1.471(1)$ & 1.467 (1) & $1.223(1)$ & $1.219(1)$ \\
\hline 25000 & $2.276(1)$ & $2.277(1)$ & $1.932(1)$ & 1.929 (1) & $1.925(1)$ & $1.481(1)$ & $1.463(1)$ \\
\hline 30000 & $2.340(1)$ & $2.342(1)$ & $2.098(1)$ & $2.098(1)$ & $2.099(1)$ & $1.779(1)$ & $1.768(1)$ \\
\hline 35000 & \multicolumn{7}{|c|}{ Internal Energy (cal/g) } \\
\hline 10000 & $7.460(3)$ & $7.460(3)$ & $7.438(3)$ & $7.438(3)$ & $7.438(3)$ & $7.428(3)$ & $7.428(3)$ \\
\hline 15000 & $1.806(4)$ & $1.791(4)$ & $1.335(4)$ & $1.330(4)$ & $1.328(4)$ & $1.184(4)$ & $1.181(4)$ \\
\hline 20000 & $1.047(5)$ & $1.034(5)$ & $4.949(4)$ & $4.884(4)$ & $4.803(4)$ & $2.634(4)$ & $2.556(4)$ \\
\hline 25000 & $1.729(5)$ & $1.732(5)$ & $1.426(5)$ & $1.421(5)$ & $1.413(5)$ & $7.903(4)$ & $7.517(4)$ \\
\hline 30000 & $1.849(5)$ & $1.854(5)$ & $1.801^{(5)}$ & $1.804(5)$ & $1.808(5)$ & $1.512(5)$ & $1.493(5)$ \\
\hline 35000 & $1.929(5)$ & $1.933(5)$ & $1.915(5)$ & $1.919(5)$ & $1.924(5)$ & $1.834(5)$ & $1.845(5)$ \\
\hline
\end{tabular}

Table 2. A comparison of thermodynamic properties at various temperatures calculated according to Margenau and Lewis's criterion (columns a), to Griem's criterion (column b) and to the ground state method (columns c) for a Nitrogen plasma.

\begin{tabular}{|c|c|c|c|c|c|c|c|}
\hline \multirow[b]{3}{*}{$T{ }^{\circ} \mathrm{K}$} & \multicolumn{2}{|c|}{$0.1 \mathrm{~atm}$. } & \multicolumn{3}{|c|}{1 atm. } & \multicolumn{2}{|c|}{10 atm. } \\
\hline & $a$ & $c$ & $a$ & & $c$ & $a$ & $c$ \\
\hline & \multicolumn{7}{|c|}{ Helmholtz Potential (cal/g) } \\
\hline 10000 & $3.215(4)$ & $3.192(4)$ & $2.866(4)$ & $2.866(4)$ & $2.843(4)$ & $2.534(4)$ & $2.511(4)$ \\
\hline 15000 & $6.239(4)$ & $6.206(4)$ & $5.323(4)$ & $5.326(4)$ & $5.270(4)$ & $4.595(4)$ & $4.518(4)$ \\
\hline 20000 & $9.812(4)$ & $9.754(4)$ & $8.509(4)$ & $8.515(4)$ & $8.444(4)$ & $7.244(4)$ & $7.151(4)$ \\
\hline 25000 & $1.380(5)$ & $1.374(5)$ & $1.190(5)$ & $1.191(5)$ & $1.181(5)$ & $1.024(5)$ & $1.013(5)$ \\
\hline \multirow[t]{2}{*}{35000} & $2.373(5)$ & $2.371(5)$ & $2.027(5)$ & $2.029(5)$ & $2.015(5)$ & $1.702(5)$ & $1.685(5)$ \\
\hline & \multicolumn{7}{|c|}{ Entropy $\left(\mathrm{cal} / \mathrm{g}{ }^{\circ} \mathrm{K}\right)$} \\
\hline 10000 & 4.501 & 4.421 & 4.004 & 4.003 & 3.916 & 3.560 & 3.455 \\
\hline 15000 & 6.562 & 6.542 & 5.359 & 5.352 & 5.321 & 4.285 & 4.162 \\
\hline 20000 & 6.993 & 6.940 & 6.255 & 6.262 & 6.212 & 5.350 & 5.319 \\
\hline 25000 & 8.140 & 8.149 & 6.655 & 6.659 & 6.599 & 5.797 & 5.740 \\
\hline 30000 & 9.410 & 9.366 & 7.744 & 7.750 & 7.721 & 6.202 & 6.129 \\
\hline 35000 & \multicolumn{7}{|c|}{ Internal Energy (cal/g) } \\
\hline 10000 & $1.286(4)$ & $1.229(4)$ & $1.138(4)$ & $1.136(4)$ & $1.072(4)$ & $1.026(4)$ & $0.944(4)$ \\
\hline 15000 & $3.604(4)$ & 3.607 (4) & $2.715(4)$ & $2.702(4)$ & $2.711(4)$ & $1.832(4)$ & $1.724(4)$ \\
\hline 20000 & $4.175(4)$ & $4.126(4)$ & $4.002(4)$ & $4.009(4)$ & $3.979(4)$ & $3.456(4)$ & $3.487(4)$ \\
\hline 25000 & $6.550(4)$ & $6.632(4)$ & $4.738(4)$ & $4.743(4)$ & $4.691(4)$ & $4.252(4)$ & $4.224(4)$ \\
\hline 30000 & $9.642(4)$ & $9.543(4)$ & $7.437(4)$ & $7.441(4)$ & $7.463(4)$ & $5.184(4)$ & $5.113(4)$ \\
\hline 35000 & $1.102(5)$ & $1.068(5)$ & $9.868(4)$ & $9.884(4)$ & $9.742(4)$ & $7.422(4)$ & $7.361(4)$ \\
\hline
\end{tabular}

electronic excitation beginns to contribute to $Q_{\mathrm{e} j}$ at temperatures at which the species $j$ has become a "minority" species in the plasma.

However, if one considers functions such as $H$ or $U$, which are dependent on $\dot{Q}_{e j}$ or the specific heats which depend on both $\dot{Q}_{\mathrm{e} j}$ and $\ddot{Q}_{\mathrm{ej}}$ this explanation becomes less satisfactory in that $\dot{Q}_{\mathrm{e} j}$ and particularly $\ddot{Q}_{\text {ej }}$ will rise above their ground state value of zero at temperatures at which the concentration of the species $j$ is still appreciable. 
A contribution of electronic excitation to these latter functions is therefore expected and the fact that this contribution is apparently absent requires closer examination. A detailed analysis of the terms into which total enthalpy and total specific heats can be separated will therefore be carried out in the next sections with reference to a nitrogen plasma.

\section{a) Total enthalpy}

The total enthalpy $H_{\text {tot }}$ of a nitrogen plasma can be calculated according to the following expression:

$H_{\mathrm{tot}}(\mathrm{cal} / \mathrm{g})=\overbrace{5 / 2 k T \sum_{j=1}^{n} N_{j}+k T \sum_{j=1}^{n} N_{j} \dot{Q}_{\mathrm{e} j}}^{H_{\mathrm{r}}}+\overbrace{\sum_{j=1}^{n} N_{j} \varepsilon_{j}}^{H_{\mathrm{r}}}$

where $N_{j}$ is the number of $j$-th particles per gram of plasma. The reference level in the nitrogen plasma has been choosen so that $\varepsilon_{\mathrm{N}_{2}}=0$. From this follows:

$$
\begin{aligned}
\varepsilon_{\mathrm{N}} & =D / 2 ; \varepsilon_{\mathrm{N}^{+}}=\left(E_{0 \mathrm{~N}}-\Delta E_{0 \mathrm{~N}}\right)+D / 2 ; \\
\varepsilon_{\mathrm{N}^{++}} & =\left(E_{0 \mathrm{~N}}-\Delta E_{0 \mathrm{~N}}\right)+\left(E_{0 \mathrm{~N}^{+}}-\Delta E_{0 \mathrm{~N}^{+}}\right)+D / 2 ; \\
\varepsilon_{\text {electron }} & =0 .
\end{aligned}
$$

with $D$ dissociation energy of the $\mathrm{N}_{2}$ molecule.

The total enthalpy can thus be thought as resulting from two contributions: the "frozen" enthalpy $H_{\mathrm{f}}$ and the "reactional" enthalpy $H_{\mathrm{r}}$.

Values of $H_{\text {tot }}, H_{\mathrm{f}}$ and $H_{\mathrm{r}}$ calculated according to the Margenau and Lewis criterion and to the ground state method have been compared in Fig. 9.

The coincidence of the values of $H_{\text {tot }}$ is indeed the result of a compensation between $H_{\mathrm{f}}$ and $H_{\mathrm{r}}$ in the two methods. In order to understand how this compensation arises, one should examine the expressions which give $H_{\mathrm{f}}$ and $H_{\mathrm{r}}$ in more detail.

In the case of a nitrogen plasma, in which successive ionizations of the species $\mathrm{N}$ are present, it is necessary, in order to simplify the problem, to consider the successive ionizations as occurring in non overlapping temperature regions ${ }^{20,21}$. In the temperature and pressure ranges considered in this work it will be sufficient to consider two ionization reactions only: 1) $\mathrm{N}=\mathrm{N}^{+}+\mathrm{e}$ and 2) $\mathrm{N}^{+}=\mathrm{N}^{++}+\mathrm{e}$. In fact $\mathrm{N}^{+++}$-ions are minority species up to $35,000{ }^{\circ} \mathrm{K}$ while the reaction $\mathrm{N}_{2}=2 \mathrm{~N}$ can be considered as completely shifted to the right above $10,000^{\circ} \mathrm{K}$.

\footnotetext{
20 J. Artmann, Z. Physik 183, 65 [1965].
}

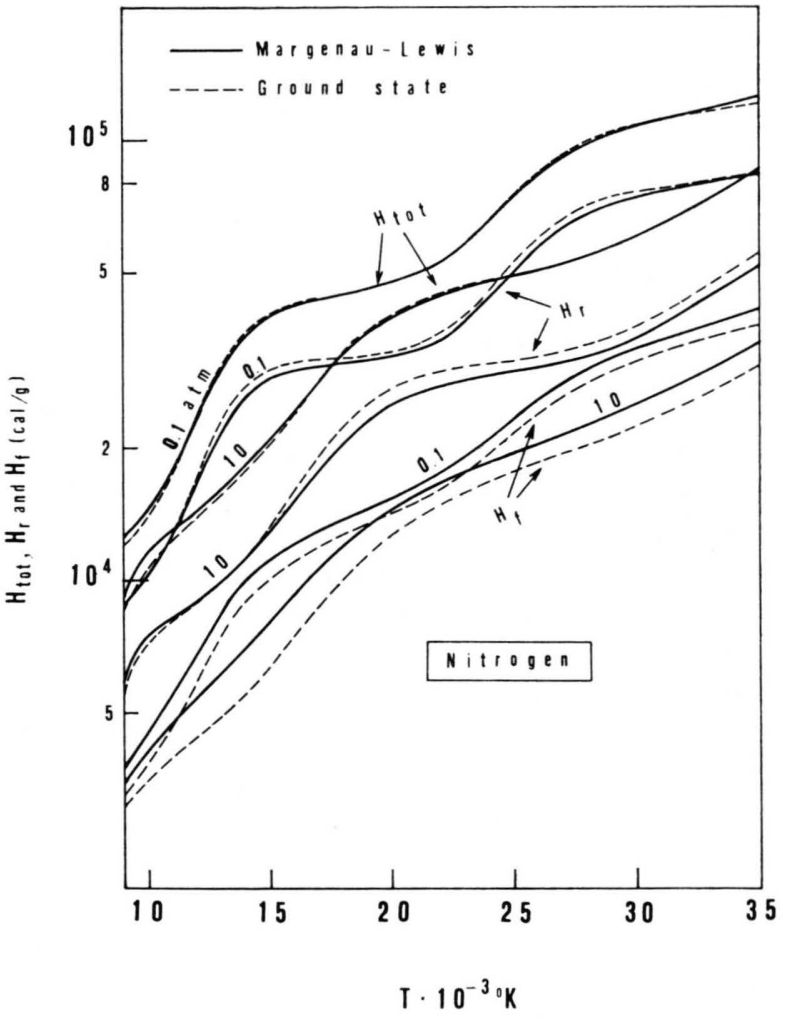

Fig. 9. Total $\left(H_{\mathrm{tot}}\right)$, reactional $\left(H_{\mathrm{r}}\right)$ and frozen $\left(H_{\mathrm{f}}\right)$ enthalpies of nitrogen at different pressures according to Margenau and Lewis and to the ground state method.

Equation (9) can be written as

$$
\begin{array}{r}
\left(H_{\mathrm{f}}\right)_{1}=5 / 2 k T\left(N_{\mathrm{e}}+N_{\mathrm{N}}+N_{\mathrm{N}^{+}}\right)+k T N_{\mathrm{N}} \dot{Q}_{\mathrm{eX}} \\
+k T N_{\mathrm{N}^{+}} \dot{Q}_{\mathrm{eN}^{+}}, \\
\left(H_{\mathrm{r}}\right)_{1}=N_{\mathrm{N}} \cdot D / 2+N_{\mathrm{N}^{+}}\left(E_{0 \mathrm{~N}}-\Delta E_{0 \mathrm{~N}}+D / 2\right)
\end{array}
$$

for reaction 1 ) and as

$$
\begin{aligned}
\left(H_{\mathrm{f}}\right)_{2}=5 / 2 k T\left(N_{\mathrm{e}}+N_{\mathrm{N}^{+}}\right. & \left.+N_{\mathrm{N}^{++}}\right)+k T N_{\mathrm{N}^{+}} \dot{Q}_{\mathrm{eN}^{+}} \\
& +k T N_{\mathrm{N}^{+}} \dot{Q}_{\mathrm{eN}^{++}}, \quad(9 \mathrm{c}) \\
\left(H_{\mathrm{r}}\right)_{2}=N_{\mathrm{N}^{+}}\left(E_{0 \mathrm{~N}}-\Delta E_{0 \mathrm{~N}}\right. & +D / 2)+N_{\mathrm{N}^{++}}\left(E_{0 \mathrm{~N}}-\Delta E_{0 \mathrm{~N}}\right. \\
& \left.+E_{0 \mathrm{~N}^{+}}-\Delta E_{0 \mathrm{~N}^{+}}+D / 2\right)(9 \mathrm{~d})
\end{aligned}
$$

for reaction 2). Equations $(9 \mathrm{a}-\mathrm{d})$ can be rearranged by introducing the first and the second degree of ionization, which are defined as

$$
\alpha_{1}=\frac{N_{\mathrm{N}^{+}}}{N_{\mathrm{N}^{+}}+N_{\mathrm{N}}} \quad \text { and } \quad \alpha_{2}=\frac{N_{\mathrm{N}^{++}}}{N_{\mathrm{N}^{+}}+N_{\mathrm{N}^{+}}} .
$$

One obtains the following expressions

$$
\begin{aligned}
\left(H_{\mathrm{f}}\right)_{1}=5 / 2 R^{*} T\left(1+\alpha_{1}\right) & +R^{*} T\left(1-\alpha_{1}\right) \dot{Q}_{\mathrm{eN}}(10 \mathrm{a}) \\
& +R^{*} T \alpha_{1} \dot{Q}_{\mathrm{eN}^{++}},
\end{aligned}
$$

21 J. Artmann, Z. Angew. Physik 25, 104 [1968]. 
$\left(H_{\mathrm{r}}\right)_{1}=\alpha_{1}\left(E_{0 \mathrm{~N}}-\Delta E_{0 \mathrm{~N}}\right)+D / 2$,

$$
\left(H_{\mathrm{f}}\right)_{2}=5 / 2 R^{*} T\left(2+\alpha_{2}\right)+R^{*} T\left(1-\alpha_{2}\right) \dot{Q}_{\mathrm{eN}^{+}}(10 \mathrm{c})
$$

$$
+R^{*} T \alpha_{2} \dot{Q}_{\mathrm{eN}^{++}},
$$

$\left(H_{\mathrm{r}}\right)_{2}=\alpha_{2}\left(E_{0 \mathrm{~N}^{+}}-\Delta E_{0 \mathrm{~N}^{+}}\right)+D / 2+E_{0 \mathrm{~N}}-\Delta E_{0 \mathrm{~N}}$.

In these derivations use has been made of the electroneutrality conditions

$$
\mathrm{N}_{\mathrm{e}}=\mathrm{N}_{\mathrm{N}^{+}} \text {and } \mathrm{N}_{\mathrm{e}}=\mathrm{N}_{\mathrm{N}^{+}}+2 \mathrm{~N}_{\mathrm{N}^{++}}
$$

which are valid for the first and for the second reaction respectively.

In Eq. $(9 \mathrm{a}-\mathrm{d})$ the energy terms $\left(D, E_{0 \mathrm{~N}}\right.$, etc.) are given in $\mathrm{cal} /$ particle while in Eq. $(10 \mathrm{a}-\mathrm{d})$ the corresponding terms are in $\mathrm{cal} / \mathrm{g}$.

One can see from Fig. 9 that $H_{\mathrm{f}}$ calculated according to the Margenau and Lewis criterion is always larger than the corresponding term calculated according to the ground state method. This problem has been discussed in connection with the reaction $\mathrm{He}=\mathrm{He}^{+}+\mathrm{e}$ in Ref. ${ }^{10}$. For reaction 1) the observed differences arise principally from the contribution of the term $k T N_{\mathrm{N}} \dot{Q}_{\mathrm{eN}}=R^{*} T\left(1-\alpha_{1}\right) \dot{Q}_{\mathrm{eN}}$. The contribution of the term $R^{*} T \alpha_{1} \dot{Q}_{\mathrm{eN}^{+}}$is on the contrary small in that $\dot{Q}_{\mathrm{eN}^{+}}$does not appreciably differ from zero until $\alpha_{1} \cong 1$, i. e. until reaction 1 ) is completed (compare Figures 2 and 10). This is the consequence of the fact that the energy levels of $\mathrm{N}^{+}$are too high to be appreciably populated in the temperature region where the species $\mathrm{N}$ ionizes. The same considerations apply to the second reaction where the term $R^{*} T\left(1-\alpha_{2}\right) \dot{Q}_{\mathrm{eN}^{+}}$is the main responsible for the observed differences.

Figure 9 also shows that the situation is reversed in the case of $H_{\mathrm{r}}$ where values derived from the ground state method are higher than those cal-

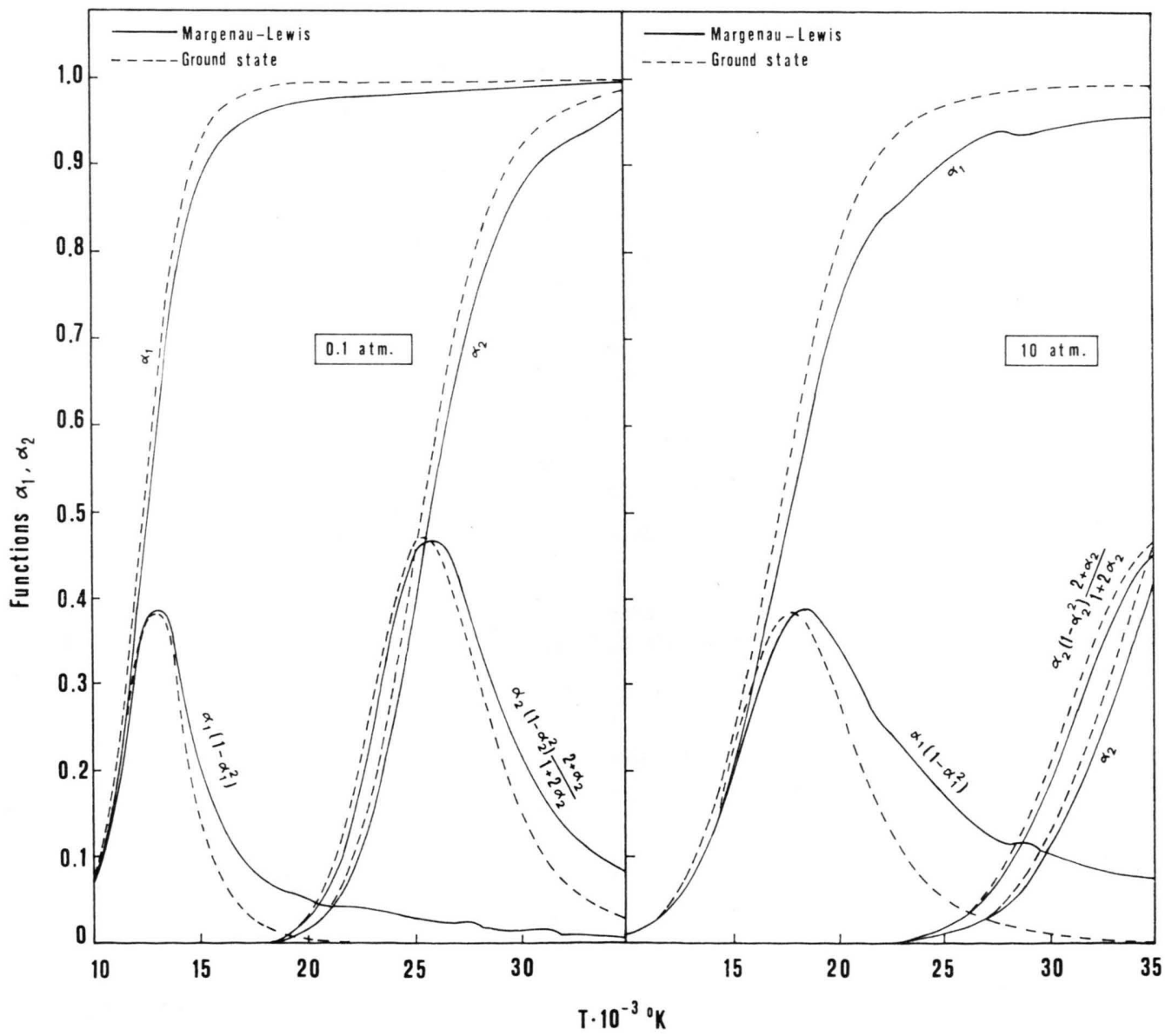

Fig. 10. Functions of $\alpha_{1}$ and $\alpha_{2}$ at 0.1 and 10 atm for nitrogen according to Margenau and Lewis and to the ground state method. 
culated with the inclusion of the energy levels. These differences can be attributed to different values of $\alpha_{1}$ and $\alpha_{2}$ [Eq. $(10 \mathrm{~b})$ and $(10 \mathrm{~d})$ ] in the two methods. In fact if one writes Saha's equation in terms of $\alpha_{1}$ and $\alpha_{2}$ one obtains ${ }^{20,} 21$

$$
\begin{gathered}
\frac{a_{1}{ }^{2}}{1-\alpha_{1}{ }^{2}} \sim \frac{T^{5 / 2}}{p} \cdot \frac{Q_{\mathrm{eN}}}{Q_{\mathrm{eN}}} \exp \left\{-\frac{E_{0} \mathrm{~N}-\Delta E_{0 \mathrm{~N}}}{k T}\right\}, \quad(11 \mathrm{a}) \\
\frac{\alpha_{2}\left(1+\alpha_{2}\right)}{\left(1-\alpha_{2}\right)\left(2+\alpha_{2}\right)} \sim \frac{T^{5 / 2}}{p} \frac{Q_{\mathrm{eN}^{++}}}{Q_{\mathrm{eN}^{+}}} \cdot \exp \left\{-\frac{E_{0} \mathrm{~N}+-\Delta E_{0 \mathrm{~N}^{+}}}{k T}\right\} .
\end{gathered}
$$

When the ground state method is applied, the ratio $Q_{\mathrm{eN}^{+}} / Q_{\mathrm{eN}}$ in Eq. (11 a) will be equal to $g_{0 \mathrm{~N}^{+}} / g_{0 \mathrm{~N}}$ and independent of temperature. When the criteria of Margenau and Lewis or of Griem are used $Q_{\mathrm{eN}}$ will increase above its ground state value beyond some pressure dependent temperature. $Q_{\mathrm{eN}^{+}}$will on the contrary remain close to $g_{0 \mathrm{~N}^{+}}$because the upper levels of $\mathrm{N}^{+}$are not appreciably populated, as already discussed. The consequence is that the ratio $Q_{\mathrm{eN}^{+}} / Q_{\mathrm{eN}}$ will decrease with increasing temperature.

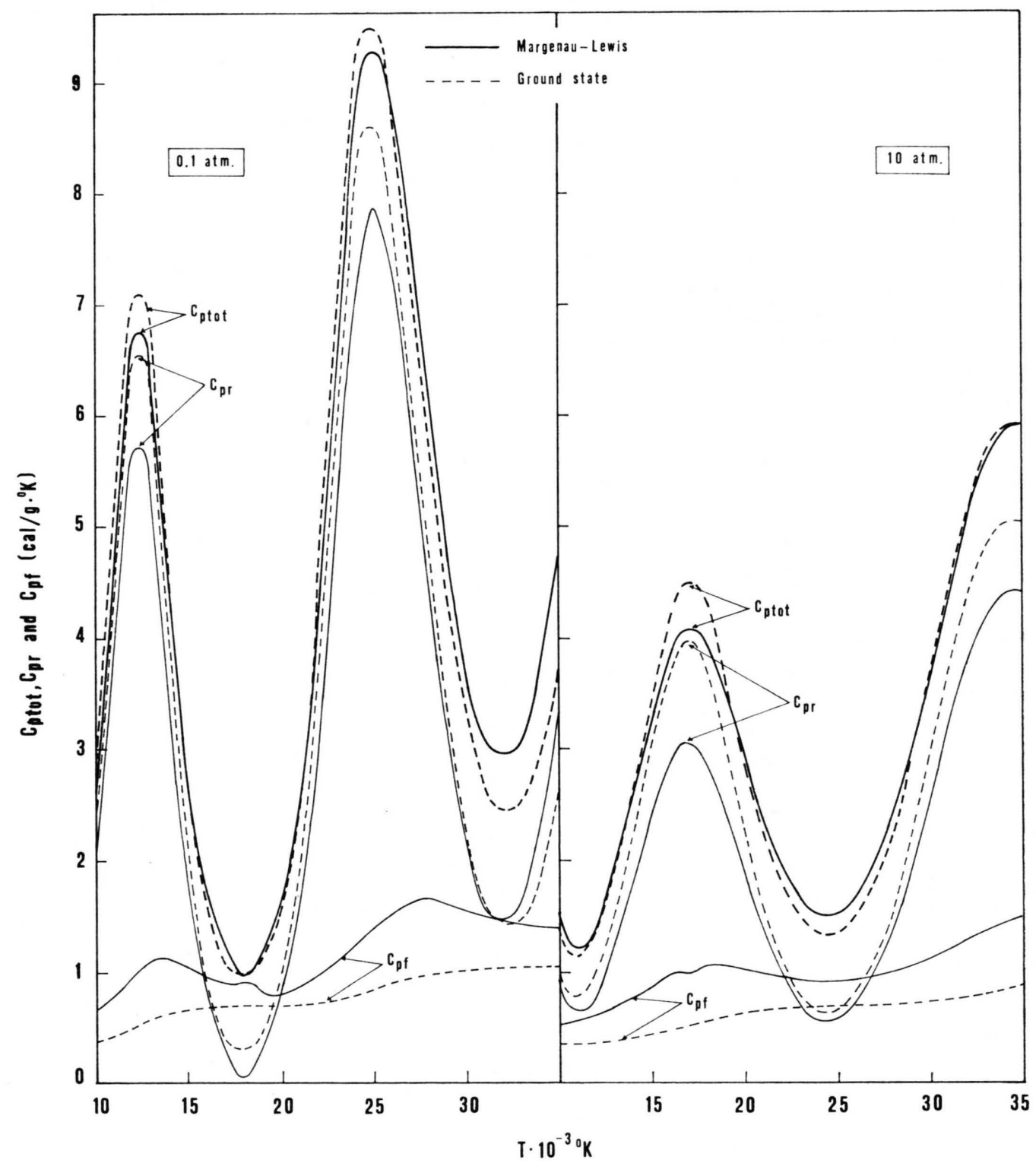

Fig. 11. Total $\left(C_{p \text {, tot }}\right)$, reactional $\left(C_{p, \mathrm{r}}\right)$, and frozen $\left(C_{p, \mathrm{f}}\right) \quad$ specific heats of nitrogen at 0.1 and 10 atm according to Margenau and Lewis and to the ground state method. 
The same considerations apply to the $Q_{\mathrm{eN}^{++}} / Q_{\mathrm{eN}^{+}}$ ratio in Eq. $11 \mathrm{~b}$. The terms $\Delta E_{0 \mathrm{~N}}$ and $\Delta E_{0 \mathrm{~N}^{+}}$in the exponentials of Eq. $11 \mathrm{a}, \mathrm{b}$, are zero in the ground state method and sufficiently small when the other criteria are adopted. The result is that values of $\alpha_{1}$ and $\alpha_{2}$ are larger when the ground state method is used. This is clearly shown in Fig. 10 and explains the observed differences in $H_{\mathrm{r}}$. Although the different methods of calculation lead to the same values of $H_{\text {tot }}$ it can now be appreciated that the situation described by the ground state method is that of a system of unexcited particles which is more ionized than the system of excited particles described by the other methods and just enough to make up for the loss of electronic excitation.

\section{b) Total specific heat}

Total specific heats $\left(C_{p, \text { tot }}\right)$ for a nitrogen plasma can be obtained by numerical derivation of Eq. 9 and frozen specific heats from the analytical derivation of $H_{\text {tot }}$ with respect to temperature at constant pressure and composition ${ }^{9}$. The difference $C_{p \text {,tot }}-C_{p, \mathrm{f}}=C_{p, \mathrm{r}}$ gives the so called "reactional" specific heat $C_{p, \mathrm{r}}$. In Fig. 11 values of these quantities calculated according to Margenau and Lewis and to the ground state method have been plotted as a function of temperature for a nitrogen plasma. The compensation between $C_{p, \mathrm{f}}$ and $C_{p, \mathrm{r}}$ to yield values of $C_{p \text {,tot }}$ which are practically independent of the method utilized is again apparent.

Compensation effects of this type have recently been discussed for the simpler case of a helium plasma ${ }^{11}$. The case of nitrogen will be examined below by resorting to the same simplifying assumption utilized in the preceding section.

The expressions for the $C_{p}$ 's corresponding to reaction 1) and 2) are the following:

$$
\begin{aligned}
& \left(C_{p, \text { tot }}\right)_{1}=\left(\frac{\partial\left(H_{\mathrm{f}}+H_{\mathrm{r}}\right)_{1}}{\partial T}\right)_{\alpha_{1}, p}+\left(\frac{\partial\left(H_{\mathrm{f}}+H_{\mathrm{r}}\right)_{1}}{\partial \alpha_{1}}\right)_{p, T}\left(\frac{\delta \alpha_{1}}{\delta T}\right)_{p} \\
& =\left(C_{p, \mathrm{f}}\right)_{1}+\left(C_{p, \mathrm{r}}\right)_{1} \text {, } \\
& \left(C_{p, \mathrm{f}}\right)_{1}=5 / 2 R^{*}\left(1+\alpha_{1}\right)+R^{*}\left(1-\alpha_{1}\right)\left(\dot{Q}_{\mathrm{eN}}+\ddot{Q}_{\mathrm{eN}}\right) \\
& +R^{*} \alpha_{1}\left(\dot{Q}_{\mathrm{eN}^{+}}+\ddot{Q}_{\mathrm{eN}^{+}}\right), \\
& \left(C_{p, \mathrm{r}}\right)_{1}=\Delta H_{1} \cdot\left(\delta \alpha_{1} / \delta T\right)_{p}, \\
& \left(C_{p, \mathrm{f}}\right)_{2}=5 / 2 R^{*}\left(2+\alpha_{2}\right)+R^{*}\left(1-\alpha_{2}\right)\left(\dot{Q}_{\mathrm{eN}^{+}}+\dot{Q}_{\mathrm{eN}^{+}}\right) \\
& +R^{*} \alpha_{2}\left(\dot{Q}_{\mathrm{eN}}{ }^{++}+\dot{Q}_{\mathrm{eN}}{ }^{++}\right), \\
& \left(C_{p, \mathrm{r}}\right)_{2}=\Delta H_{2} \cdot\left(\delta \alpha_{2} / \delta T\right)_{p},
\end{aligned}
$$

$$
\begin{aligned}
& \Delta H_{1}=5 / 2 R^{*} T+R^{*} T\left(\dot{Q}_{\mathrm{eN}^{+}}-\dot{Q}_{\mathrm{eN}}\right)+E_{0 \mathrm{~N}}-\Delta E_{0 \mathrm{~N}}, \\
& \Delta H_{2}=5 / 2 R^{*} T+R^{*} T\left(\dot{Q}_{\mathrm{eN}^{++}}-\dot{Q}_{\mathrm{eN}^{+}}\right)+E_{0 \mathrm{~N}^{+}}-\Delta E_{0 \mathrm{~N}^{+}}, \\
& \left(\frac{\delta a_{1}}{\delta T}\right)=\frac{\alpha_{1}}{2}\left(1-\alpha_{1}^{2}\right) \frac{1}{k T^{2}} \Delta H_{1} ; \\
& \left(\frac{\delta \alpha_{2}}{\delta T}\right)=\frac{\alpha_{2}}{2}\left(1-\alpha_{2}^{2}\right) \frac{\left(2+\alpha_{2}\right)}{\left(1+2 \alpha_{2}\right)} \frac{1}{k T^{2}} \Delta H_{2} .
\end{aligned}
$$

Values of $\Delta H_{1}, \Delta H_{2}$ in Eq. $(12 \mathrm{c}, \mathrm{e}, \mathrm{f}, \mathrm{g})$ are in $\mathrm{cal} / \mathrm{g}$, in Eq. (12 h, i) in cal/particle.

The differences in the values of the $C_{p, \mathrm{f}}$ 's can be ascribed to the second term of Eq. (12 b, d) where the largest contribution to the observed differences comes from $\ddot{Q}_{\mathrm{eN}}$ in $(12 \mathrm{~b})$ and from $\ddot{Q}_{\mathrm{eN}^{+}}$in $(12 \mathrm{~d})$, see Fig. 3.

Values of $C_{p, \mathrm{r}}$ differ in the two methods because values of $\Delta H_{1}$ and $\Delta H_{2}$ are different (Fig. 6) and because the functions

$$
\alpha_{1}\left(1-\alpha_{1}^{2}\right) \text { and } \frac{\alpha_{2}\left(1-\alpha_{2}{ }^{2}\right)\left(2+\alpha_{2}\right)}{1+2 \alpha_{2}}
$$

in Eq. (12 h, i), are also different (Fig. 10).

The conclusion is that the terms into which $C_{p, \mathrm{f}}$ and $C_{p, \mathrm{r}}$ can be separated are all dependent on the criterion adopted, i.e. they all depend on electronic excitation. The sum of $C_{p, \mathrm{f}}$ and $C_{p, \mathrm{r}}$ is indeed independent of the method utilized in the calculations but it should now be clear that this does not

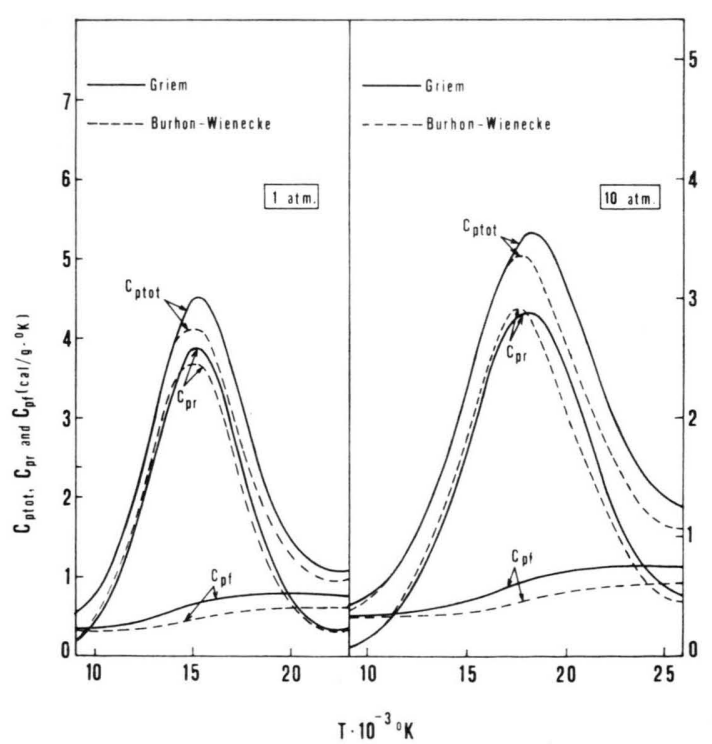

Fig. 12. Total $\left(C_{p, \text { tot }}\right)$, reactional $\left(C_{p, \mathrm{r}}\right)$, and frozen $\left(C_{p, \mathrm{f}}\right)$ specific heats of oxygen at $1-10$ atm according to Griem and to Burhon and Wienecke. 